\title{
Influence of Mulching and Seed Planting Date on Cotton Productivity
}

\author{
Akhmurzaev Shavkat Isakovich \\ Independent researcher, Department of Husbandry and Melioration, Tashkent State Agrarian University, \\ Tashkent-100140, University str.,3, Uzbekistan
}

\begin{abstract}
The role of methods and terms of mulching in the increasing of cotton productivity was announced in the article. At the present time with the challenges of water shortage, to retain the soil moisture and application of methods on rationally using of water are very important. Unconventional mulching materials as films (transparent and black), plant residues (rice husk and wheat hey) and polymers (SAG and MT preparations) as solutions have been applied in the experiments. On the base of taken data it was exhibited that they have positive impacts on physical property of soil and cotton development. In the result, the high yield (32.8 c/ha) an average for three years was taken in the $1^{\text {st }}$ planting term with the application of transparent film. The extra yield than control variant consisted of $5.9 \mathrm{c} / \mathrm{ha}$. This index than $2^{\text {nd }}$ term of planting is differentiated only for $0.5 \mathrm{c} / \mathrm{ha}$. The following places, correspondingly to planting terms were devoted to black film (30,9-31,2 c/ha), MT preparation (29,9-31,1 c/ha) and rice husk (28,8-30,8 c/ha).
\end{abstract}

Keywords: meadow alluvial, mulch materials, film, wheat hey, rice husk, preparations, heat regime, water-physical property, productivity

\section{Introduction}

Increasing of temperature on the face of soil for several grades at the beginning of cotton growth providing the best growth and its precocity, has great agronomic and economic significance. For accelerating of cotton development and getting of abundant and early yield it is necessary to accomplish the whole complex of measures, closely connected with each other by taking into account soilclimatic conditions of locality.

It is known that peat, sand, hey, leaves and manure are used as the means of mulching. Their applying on the surface of soil at the certain depth keeps soil moisture, improving its texture. Besides, as a result of mulching the moisture evaporation decreases, the sun light restricts, soil temperature increase $[4,5]$.

At the time of experiments, it was observed that growth and development of cotton have enhanced in the mulching by polyethylene in comparison with control variant. Phonological survey on the first of August pointed out that the main stock of cotton was higher for $10-13 \mathrm{~cm}$, yield components for 1.5-2.2 units more, amount of bolls for 4-5 pair more, the time of blooming has begun for 5-6 days earlier.

\section{Materials and Methods}

The Research works were carried out at training experimental farm of the TSAU during 2009-2013 with the purpose of studying of mulching materials influence on growth, development and cotton productivity. The soil of experimental field is weeded alluvial, with ground water at the depth of $1.5 \mathrm{~m}$.

Delinted seeds of the variety "Namangan-77" belonging to the middle-staple cotton were planted by the scheme of $90 \times 10-1$, the variants of experiment were carried out in 4 replications, every variant had 8 rows by width of $0.2 \mathrm{~m}$, the length was $50 \mathrm{~m}$. The total area of lots consisted of $360 \mathrm{~m}^{2}$, accounting area $-180 \mathrm{~m}^{2}$ [3].

The experiments were carried out in the following variants:

1) Control (without mulching);

2) Mulching by light transparent film;

3) Mulching by black film;

4) Mulching by rice husk;

5) Mulching by wheat hey;

6) Mulching by CAT preparation;

7) Mulching by MT preparation.

The impact of mulching materials in two dates of planting was studied. The growth, development and productivity of cotton connected with the dates of sowing and methods of mulching were determined.

\section{Results and Discussion}

The effect of mulching materials by accelerating of seedling's sprouting and continues in successive periods of development $[1,2,6]$. Planting of cotton was carried out in two terms: the first on April 7-12, the second on April 22-24. The influence of mulching materials on growth of main stock, number of branches and buds of cotton plant has been observed on the term of sowing. On the indexes of August 1, the height of main stock made $100.3 \mathrm{~cm}$ (an average for 2 years), fruiting branches -12.1 units, the bolls of September 1 were 8.2 pairs, including opened bolls $-29.0 \%$ in the control variant. In the variant with transparent film these indexes were correspondingly equal to: $109.6 \mathrm{~cm} ; 14.1 ; 10.9$ $\mathrm{cm}, 56.8 \%$, in comparison with control variant were higher for: $9.3,2.0$ and 2.7 pairs and $27.8 \%$.

In the variant with black film, those indexes correspondingly composed of: $107.9 \mathrm{~cm}$; 12,7; 9.6 pairs; $53.2 \%$ in comparison with control variant correspondingly were for: $7.6 \mathrm{~cm} ; 0.6$ and 1.4 pair, $24.2 \%$. But in comparison with indexes of transparent film these data were low for $1.7 \mathrm{~cm}$, 1.4 and 1.3 pair, $3.0 \%$. 


\section{International Journal of Science and Research (IJSR) \\ ISSN (Online): 2319-7064}

Index Copernicus Value (2016): 79.57 | Impact Factor (2015): 6.391

The transparent film in comparison with black film lets in the light to the surface of soil better and the temperature of soil increases. As a result, the seedlings germination speeds and positively affects on the cotton development $[4,5]$.

In usage of rice husks, the above mentioned indexes correspondingly made: $101.0 \mathrm{~cm} ; 12.4$ and $8.8 \mathrm{pcs}, 41.5 \%$. These figures in comparison with control variant were higher for $0.7 \mathrm{~cm} ; 0.3$ and $0.6 \mathrm{pcs}, 12.5 \%$, but the number of opened bolls in comparison with variant indexes, where rice husk and wheat hey were used has almost been insignificant. Otherwise, it was found that in the mulching by the plants residues their effect on growth and development of cotton plant was almost similar.

In polymers application, the preparation MT was proved to be more output in the growth and development of cotton plant. In the variant with usage of preparation MT on August 1 , the height of main stock was $103.6 \mathrm{~cm}$, fruiting branches - 13.3; the number of bolls (on September 1) -9.3 pcs, including opened- $49.6 \%$, and the indexes of preparation SAG correspondingly, formed less for $0.7 \mathrm{~cm}$; 0.6 and 0.4 pcs and $4.0 \%$.

In the second term of planting, the influence of mulching materials on growth and development of cotton in comparison with first term was slightly less.

In using of polyethylene film, the height of main stock correspondingly made: $109.4-107.5 \mathrm{~cm}$, fruiting branches 14.4-13.5 pcs, bolls -11.0-9.6 pairs, including opened -55.8$53.4 \%$. These indexes in comparison with control variant were more for 7.1-5.2 cm; 1.9-1.0 and 1.6-0.2 pcs and 24.6$22.2 \%$. Correspondingly, the speed of bolls opening at the first term of planting under the influence of mulching has been high.

In using of plant residues (rice husk, wheat hey) and polymers (SAG and MT) conformity to above noted laws has been retained. Hence, the influence of mulching materials on growth and development of cotton at the first planting term was high.

The variants by films mulching (transparent and black) on the first planting term have yielded 31.3-29.0 c/ha. This is more for 5.6-3.3 c/ha in comparison with control. The variants by using of plants residues (rice husk and wheat hey) the shares of yields $-27.2-26.8 \mathrm{c} / \mathrm{ha}$, that is for 1.5-1.1 $\mathrm{c} / \mathrm{ha}$ more than in control one, but in comparison with indexes of variants with polyethylene films correspondingly lower for 4.1-1.8 and 4.5-2.2 c/ha. the variants with polymers (SAG and MT) also have the highest indexes. At this the yield of raw cotton made 27.2-28.3 c/ha, in comparison with control, it was more for $1.5-2.6 \mathrm{c} / \mathrm{ha}$.

At the second term of planting, the variants mulched by films gave 31.5-30.5 /ha than in control variant. At the using of plants residues (rice husk and wheat hey) this indexes made $29.7-30.1 \mathrm{c} / \mathrm{ha}$ and this is for $1.4-1.8 \mathrm{c} / \mathrm{ha}$ more than in control one, but in comparison with variants, where films applied, correspondingly lower for 1.8-0.8 and 1.4-0.4 c/ha. In variants of mulching with polymers (SAG and MT) the indexes were also high than in control variant. Here, the yield of cotton made up 30.1-30.8 c/ha, this is more for 1.8 $2.5 \mathrm{c} /$ ha in comparison with control.

\section{Conclusions}

Despite the fact that experimental works in all variants, the cotton planting was carried out for 10-11 days later, the yield of raw cotton in comparison with the first term was more for 0.2-3.3 c/ha. But the efficiency of used mulching materials was quite the reverse, for 1-2 c/ha lower in comparison with the first term.

This condition may be explained by those that the weather at the second term became warmer and the temperature of the soil increased and in the result of which the best condition for appearing of rapid seedlings was established. The index of positive influence of mulching materials on growth and development of cotton plant irrespective of the kind of materials and planting terms of cotton seeds was defined. The best indexes were obtained at using of films, after them - the effects of polymers and the last is plant residues. Their effect was slightly higher at the first term in comparison with the second one.

In conclusion it is necessary to emphasize that the methods of mulching are needed to get an abundant and early yields of cotton. The earlier planting of cotton seeds is required in order to enhance its efficiency. The productivity is also increased for 3.3-5.6 c/ha on the account of mulching with transparent and black films, and at the expense of polymers for 2.2-4.5 c/ha in comparison of control variant.

\section{References}

[1] Bezborodov G.A., Esanbekov M.Yu. Scientific base of watering by mulching of cotton rows with winter wheat hey. Water and resource saving technologies in agriculture of Uzbekistan (themes of conference), 63 67, 2008. Tashkent (in Uzbek).

[2] Diyorov G.Q., Turapov I.T. The influence of mulching technology of soil surface with the polyethylene films decomposing in the conditions of typical meadow soils on soil agro physical properties. J. Bulletin of the agrarian science of Uzbekistan. № 1, 57-59. 2003. Tashkent (in Uzbek).

[3] Dospekhov B.A. Methods field experience. 1985. Agropromizdat, Moskow $5^{\text {th }}$ edition, 350 p. (in russian).

[4] Ermatov A., Akhmirzaev SH. The influence of cotton seed planting term and mulching methods on soil agro chemical properties. J. Bulletin of the agrarian science of Uzbekistan. № 1-2, 116-117. 2012. Tashkent (in Uzbek).

[5] Gizaev U.L., Muradova O.I., Akhmirzaev SH.I. The influence of ecological factors on cotton productivity. Scientific papers collection on the topic of "Climate changing and rational using of natural resources". 4850. 2012, Tashkent (in Uzbek).

[6] Yakubjanov O., Toshboltaev M. The factors of profitable and early cotton growing in the Andijan region. Agriculture of Uzbekistan, №6, 33-34. 2000 (in Uzbek).

\section{Volume 6 Issue 12, December 2017}

